Received: 2021/07/28, Revised: 2021/08/31

Accepted: 2021/09/03, Published: 2021/09/30

๑2021 II-Su Kwon et al.; Licence Physical Activity and Nu-

trition. This is an open access article distributed under the

terms of the creative commons attribution license (https:/l

creativecommons.org/licenses/by-nc/2.0/), which permits

unrestricted use, distribution, and reproduction in any medi-

um, provided the orginal work is properly cited.

*Corresponding author : Jae-Keun Oh

Department of Health and Exercise Science, Korea Na-

tional Sport University, 1239 Yangjae-daero, Songpa-gu, Seoul, Republic of Korea.

Tel: +82-2-410-6700 / Fax: +82-2-418-1877

E-mail: ojk8688@hanmail.net

@2021 The Korean Society for Exercise Nutrition

\section{Effects of marine oligomeric polyphenols on body composition and physical ability of elderly individuals with sarcopenia: a pilot study}

\author{
Il-Su Kwon ${ }^{1}$ / Deuk-Su Park ${ }^{1}$ / Hyeon-Cheol Shin ${ }^{2}$ / \\ Myung-Gyu Seok ${ }^{3}$ / Jae-Keun $\mathbf{O h}^{1 *}$
}

1. Department of Health and Exercise Science, Korea National Sport University, Seoul, Republic of Korea

2. Botamedi Inc., Seoul, Republic of Korea

3. Department of Physical Education, Kyung Hee University, Seoul, Republic of Korea

\section{INTRODUCTION}

[Purpose] We aimed to identify the effects of marine oligomeric polyphenol (MOP) intake in elderly individuals with sarcopenia

[Methods] Older adults (aged 65 years or older) were recruited based on the diagnostic criterion for sarcopenia and were randomly assigned to the MOP intake group $(n=10)$ or the placebo (PBO) intake group $(n=10)$. To determine the effect of MOP intake received for four weeks, the pre- and post-intake body composition (weight, skeletal muscle mass, and bone density) and senior fitness tests were assessed.

[Results] Our results showed there were significant differences in the skeletal muscle mass $(p=0.039)$, bone density $(p=0.020)$, fat-free mass index $(p=0.026)$, and $2.4 \mathrm{~m}$ up and go test $(p=0.001)$ between pretest and post-test. There was a significant difference between the pre-test and post-test and an interaction effect for the one-leg stand test $p=0.010$ and $p=0.049$, respectively). However, there were no significant differences in body fat percentage, calf circumference, grip strength, or the chair rise test.

[Conclusion] Some variables exhibited significant differences in the pre- and post-assessments, and there was an interaction effect for the one-leg stand. However, this was insufficient to prove the effectiveness of MOP intake in improving sarcopenia. Therefore, additional studies are essential to examine the effects of MOP intake and exercise intervention on the body composition and fitness of patients over a longer period.

[Key words] Sarcopenia, marine oligomeric polyphenols, body composition, senior fitness test
In Korea, the proportion of adults aged 65 years or older was $7.2 \%$ in 2000 and $14.3 \%$ in 2018 . This proportion is expected to exceed $20 \%$ by $2025^{1}$.

In terms of health problems among older adults, $86.7 \%$ have had one or more chronic illnesses, and $30.8 \%$ have had minor disabilities, making daily life difficult. Thus, the health problems of older adults are considered an important social issue. Furthermore, $10.5 \%$ of the elderly experience difficulties in their daily lives, indicating the severity of health problems of older adults. This is caused by biological changes associated with aging. In particular, skeletal muscle mass (SMM) reduction and bone density weakening are substantial with increasing age ${ }^{2}$.

Sarcopenia refers to a degenerative reduction in muscle mass and strength caused by aging. It is accompanied by gait speed reduction and a decline in physical functions ${ }^{3}$. Sarcopenia is strongly associated with senescence ${ }^{4}$. It was recently registered in the International Classification of Disease (2016) as ICD-10-CM code M62.84. Improvement plans are necessary since social costs due to sarcopenia are increasing ${ }^{5}$. The causal mechanisms of sarcopenia have shown that oxidative stress, pro-inflammatory cytokines, and sex steroids are the major factors contributing to the development of sarcopenia ${ }^{6-8}$.

Aging affects the catabolism of muscle proteins. Based on the oxidative stress theory of aging, aging is caused by the accumulation of oxidative damage to proteins by reactive oxygen (ROS) and nitrogen species ${ }^{9}$. This damage to proteins plays a major role in muscle atrophy via the ubiquitin-proteasome pathway ${ }^{10}$.

Food intake helps prevent and alleviate sarcopenia, and essential amino acids promote protein synthesis ${ }^{11}$. Furthermore, exercise and appropriate protein and energy intake are necessary to prevent and manage sarcopenia, and the provision of protein could help reduce muscle loss. Substances such as leucine, amino acids, and creatine can increase strength $^{12}$.

Several studies have reported the beneficial effects of marine polyphenols in reducing inflammation-related conditions, achieved by its action 
on enzymatic and non-enzymatic inflammatory targets ${ }^{13}$. Seaweeds are widely used in food, nutraceutical, pharmaceutical, and industrial companies because of their advantages to human health ${ }^{14}$. Currently, marine algal polyphenols have been shown to have beneficial effects on muscle cells and can induce muscle cell growth; however, additional in vivo tests are required ${ }^{15}$. Moreover, seaweed is of importance because it assures soils and crops are free from chemicals; thus, it is advantageous for human health ${ }^{14}$.

The antioxidant properties of food containing polyphenols include the inhibition of oxidative stress. According to a study by Fernado et al. ${ }^{16}$, polyphenolic compounds isolated from marine algae exhibited various beneficial biological properties. Many polyphenols are used in beauty, health, and medical products after their extraction from land-based plants and marine plants, such as those of Phaeophyceae and Rhodophyceae families. In particular, phlorotannins, which are polyphenols extracted from members of Phaeophyceae, are based on various phloroglucinol compounds and have phenyl and phenoxy with low, medium, and high molecular weights ${ }^{17}$. Phlorotannins have various biological effects, such as antioxidant, anticancer, antidiabetic, antiviral, and antihypertensive effects. Additionally, they suppress the levels of matrix metalloproteinase enzymes in cancer cells and have anti-allergy functions and protective effects against radiation ${ }^{18}$. Recently, numerous studies have reported polyphenols as effective bioactive molecules that attenuate muscle atrophy and enhance muscle health ${ }^{19}$. However, the studies focused on marine oligomeric polyphenols (MOPs) for the sarcopenic elderly are limited.

Therefore, the goal of this study was to investigate the effects of the intake of food with MOPs extracted from Phaeophyceae in older adults with sarcopenia by observing the changes in body composition (body fat percentage, body mass index [BMI; \%BF]), SMM, bone density, calf circumference, and senior fitness test indices (grip strength, chair rise test, gait speed, and balance). We also provide supportive methods to improve sarcopenia in older adults.

\section{METHODS}

\section{Participants}

Older adults aged 65 years or older who were registered at the K Senior Welfare Service Center in Seoul were recruited for this study. They participated in similar programs at the same center and had similar living patterns. A total of 26 patients who did not undergo internal or orthopedic surgery or treatment within the last 6 months and did not have limitations regarding participation in this study according to expert consultation through a medical interview were included. An explanatory statement was written if there were abnormal symptoms or a patient requested to drop out of the study, and the patient was excluded $(n=6)$. We excluded participants who had uncontrollable chronic diseases. The remaining patients were randomly assigned to the MOP intake group $(\mathrm{n}=10 ;$ men $=2$, women $=8)$ or the placebo $(\mathrm{PBO})$ intake group $(\mathrm{n}=10 ; \mathrm{men}=2$, women $=8)$.
All patients were informed about the purpose of this study, the ingredients of foods, duration of intake, and measurements. Voluntary consent was obtained before the study. The characteristics of the study participants are shown in Table 1. This study was approved by the Korea National Sport University Institutional Review Board and was conducted in accordance with the 1975 Declaration of Helsinki guidelines (IRB number: 1263-202006-HR-037-03).

Table 1. Patient baseline characteristics $(n=20)$.

$\begin{array}{ccccc} & \text { Age (years) } & \text { Height }(\mathbf{c m}) & \text { Weight }(\mathrm{kg}) & \text { ALM } \\ \text { MOP } & 74.63 \pm 9.30 & 154.44 \pm 13.39 & 59.66 \pm 12.37 & 14.56 \\ \text { PBO } & 73.38 \pm 10.66 & 154.80 \pm 6.99 & 60.56 \pm 9.48 & 15.01 \\ \text { P } & 0.806 & 0.947 & 0.873 & 0.682\end{array}$

MOP: Marine oligomeric polyphenol, PBO: Placebo, ALM: Appendicular Lean Mass (sum of lean mass from both arms and legs).

\section{Criteria for sarcopenia}

Sarcopenia refers to a decline in muscle mass, strength, and physical performance ${ }^{3}$. As a standard, appendicular lean mass (ALM; the sum of lean mass from both arms and legs) suggested by Studenski and colleagues ${ }^{20}$ was used: If the ALM value was below $15.02 \mathrm{~kg}$ for women or $19.75 \mathrm{~kg}$ for men, a patient was diagnosed with sarcopenia.

\section{Measurements and variables}

\section{Body composition}

The Inbody770 (InBody Co. Korea Measurement, Korea) measured the SMM, BMI, and body fat percentage. In accordance with the ACSM guidelines ${ }^{21}$, all measurements were made once the patients changed into comfortable clothes. Additionally, food and fluid intake and strenuous physical activities were limited within $2 \mathrm{~h}$ of measurement.

Measurements using dual-energy X-ray absorptiometry

To identify the changes in bone density (t-score) and the fat-free mass index (\%FFMI), dual-energy X-ray absorptiometry (DEXA; Lunar Prodigy, GE Medical Systems, Waukesha, USA) was used. DEXA has high reliability for measuring changes in partial and overall body composition ${ }^{22}$.

\section{Anthropometry}

For calf circumference, the thickest part of the calf was measured with a measuring tape while the patient sat straight with their knees bent at $90^{\circ}$ angles ${ }^{15}$.

\section{Grip strength}

A dynamometer (Takei, Japan) was used to measure grip strength. The patient sat up straight in a chair and bent their arm approximately $15^{\circ}$ away from the body. Then, the patient held the dynamometer such that the second joint of the fingers formed a right angle, and the measurement was taken. Measurements were taken twice; first for the left and then the right hand. The higher value was used ${ }^{23}$.

\section{Chair rise test}

The chair rise test is a method used to measure lower 
body muscle power in older adults. The patient was asked to sit on a $45 \mathrm{~cm}$-tall chair. The patient held his or her arms against their chest, and the measurement was taken five times without rest at maximum speed when the patient was ready to sit and rise from the chair ${ }^{24}$.

\section{The $2.4 \mathrm{~m}$ up and go test}

The purpose of the $2.4 \mathrm{~m}$ up and go test was to assess agility and dynamic balance. A chair was placed against the wall, and a cone was placed $2.4 \mathrm{~m}$ ahead of the chair. The patient sat in the middle of the chair with his or her back straightened. The patient placed their hands on their thighs, and their feet were placed flat on the ground. When the "go" signal was given, the patient rose from the chair, circled the cone, and walked back to sit down as quickly as possible. The time spent to accomplish this task was measured. The shortest time duration among the two attempts was record$\mathrm{ed}^{25}$.

\section{One-leg stand test}

To measure static balance, a one-leg stand test was performed. This method can qualitatively and easily measure balance ${ }^{26}$. In this study, the patients lifted their leg behind themselves and bent the respective knee at $90^{\circ}$ with their eyes open. The time taken for the lifted foot of the patient to touch the floor was measured twice. The longest duration was considered for this study.

\section{Method of intake}

Patients were instructed to dissolve one spoon $(0.7 \mathrm{~g})$ of Mannas $^{\mathrm{TM}}$ (developed by BotaMedi, Inc.), which contained MOP, in $500 \mathrm{ml}$ of water. They were instructed to drink the solution on an empty stomach after waking up and before sleeping each day for 4 weeks. Mannas powder products consist of $99 \%$ dextrin $+1 \%$ MOP. The PBO drink was made with dextrin to have a similar flavor and taste. The PBO group was instructed in a similar manner. To determine whether the participants consumed the products each day, both the welfare center employees and the research team performed phone monitoring. The dose was determined according to a study wherein the best dose to improve endurance was obtained by ingesting $72 \mathrm{mg}$ (dissolved form $180 \mathrm{~mL}$ ionized beverage) in a single dose of "ECP," which substantially is the same ingredient as MOP${ }^{27}$.

\section{Data analysis and statistical methods}

Descriptive statistics (mean, standard deviation) were calculated for all data from this study using SPSS version 21.0. A two-way analysis of variance with repeated measures was performed to evaluate changes in body composition and fitness over time and between groups according to food intake. The difference between the periods was determined using the Wilcoxon test, and the difference between the groups was evaluated using the Mann-Whitney U test. The statistical significance level for all tests was set at $\alpha=0.05$.

\section{RESULTS}

\section{Changes in the body composition due to MOP in- take}

Body composition

When changes in the body composition were analyzed after MOP intake, there was a statistically significant increase in the SMM between the pre-test and post-test period $(\mathrm{F}=5.184, p=0.039)$ (Table 2). There were no significant

Table 2. Changes in the BIA.

\begin{tabular}{|c|c|c|c|c|c|c|}
\hline & Group & Pre-test & Post-test & $\mathbf{F}$ & \multicolumn{2}{|c|}{ Significance } \\
\hline \multirow{3}{*}{$\begin{array}{l}\text { Weight } \\
(\mathrm{kg})\end{array}$} & MOP & $59.66 \pm 12.37$ & $60.03 \pm 12.94$ & 2.691 & $\mathrm{~T}:$ & 0.123 \\
\hline & & & & 0.031 & $\mathrm{t} \times \mathrm{g}:$ & 0.862 \\
\hline & PBO & $60.56 \pm 9.48$ & $61.01 \pm 9.61$ & 0.028 & G: & 0.869 \\
\hline \multirow{3}{*}{$\begin{array}{l}\text { SMM } \\
(\mathrm{kg})\end{array}$} & MOP & $20.98 \pm 5.56$ & $21.31 \pm 5.73$ & 5.184 & $\mathrm{~T}:$ & $0.039^{*}$ \\
\hline & & & & 1.296 & txg: & 0.274 \\
\hline & PBO & $21.21 \pm 2.39$ & $21.33 \pm 2.63$ & 0.003 & $\mathrm{G}:$ & 0.955 \\
\hline \multirow{3}{*}{$\mathrm{BMI}$} & MOP & $24.86 \pm 3.19$ & $24.99 \pm 3.53$ & 1.707 & $\mathrm{~T}:$ & 0.212 \\
\hline & & & & 0.068 & t×g: & 0.798 \\
\hline & PBO & $25.39 \pm 4.46$ & $25.58 \pm 4.47$ & 0.08 & G: & 0.782 \\
\hline \multirow{3}{*}{$\% B F$} & MOP & $33.76 \pm 9.38$ & $33.15 \pm 9.63$ & 0.222 & $\mathrm{~T}:$ & 0.645 \\
\hline & IVIUT & $30.10 \pm 9.00$ & 30.1019 .03 & 1.703 & txg: & 0.213 \\
\hline & PBO & $33.28 \pm 11.01$ & $33.56 \pm 10.85$ & 0 & G: & 0.994 \\
\hline \multirow{3}{*}{$\begin{array}{l}\text { Body water } \\
\text { (L) }\end{array}$} & MOP & $28.94 \pm 6.82$ & $29.30 \pm 7.04$ & 3.137 & $\mathrm{~T}:$ & 0.098 \\
\hline & & & & 0.869 & txg: & 0.367 \\
\hline & PBO & $29.20 \pm 3.23$ & $29.31 \pm 3.44$ & 0.003 & G: & 0.960 \\
\hline \multirow{3}{*}{$\begin{array}{l}\text { Intracellular fluid } \\
\text { (L) }\end{array}$} & MOP & $17.61 \pm 4.26$ & $17.88 \pm 4.37$ & 5.777 & $\mathrm{~T}:$ & $0.031^{*}$ \\
\hline & & & & 1.444 & $\mathrm{t} \times \mathrm{g}:$ & 0.249 \\
\hline & PBO & $17.80 \pm 1.83$ & $17.89 \pm 2.02$ & 0.004 & G: & 0.953 \\
\hline \multirow{2}{*}{$\begin{array}{l}\text { Extracellular fluid } \\
\text { (L) }\end{array}$} & MOP & $11.33 \pm 2.56$ & $11.43 \pm 2.67$ & 0.916 & $\mathrm{~T}:$ & 0.355 \\
\hline & PBO & $11.40 \pm 1.41$ & $11.43 \pm 1.42$ & 0.330 & $t \times g:$ & 0.575 \\
\hline
\end{tabular}

Values are expressed as the mean \pm standard deviation. ${ }^{*} p<0.05, T=$ time, $G=$ group, MOP: Marine oligomeric polyphenol, PBO: placebo, BIA: bioelectric impedance analysis, $\mathrm{t} \times \mathrm{g}=$ interaction of time and group. 
differences in weight, BMI, or body fat percentage between the groups. Furthermore, there was a statistically significant increase in the intracellular fluid between the pre-test and post-test period $(\mathrm{F}=5.777, p=0.031)$. There were no significant differences in body water or extracellular fluid.

Dual-energy X-ray absorptiometry

Bone density ( $t$-score)

Changes in the body composition based on MOP intake exhibited a statistically significant increase between the pretest and post-test period $(\mathrm{F}=6.929, p=0.020)$ (Table 3$)$. There were no group or interaction effects.

\section{$\% F F M I$}

The \%FFMI exhibited a statistically significant increase between the pre-test and post-test period $(\mathrm{F}=6.206, p=0.026)$ (Table 3). There were no group or interaction effects.

\section{Lean body mass $(\mathrm{kg})$}

Lean body mass exhibited a statistically significant increase between the pre-test and post-test period $(\mathrm{F}=7.154$, $p=0.018$ ) (Table 3 ). There were no group or interaction effects.

\section{Calf circumference}

The calf circumference exhibited non-significant differences for time, group, and interaction effects (Table 4).

\section{Grip strength}

Grip strength exhibited non-significant differences for time, group, and interaction effect (Table 5).

\section{The $2.4 \mathrm{~m}$ up and go test}

The $2.4 \mathrm{~m}$ up and go test showed a statistically significant difference between the pre-test and post-test period $(\mathrm{F}=16.537, p=0.001)$ (Table 5). There were no group or interaction effects.

\section{Chair rise test}

The chair rise test outcomes showed no statistically significant differences for time, group, and interaction effects (Table 5).

\section{One-leg stand test}

The one-leg stand test exhibited statistically significant difference between the pre-test and post-test period $(\mathrm{F}=8.836$, $p=0.01)$ and interaction effects $(\mathrm{F}=4.651, p=0.049)$ (Table 5). No group effects were observed.

Table 3. Changes in DEXA measurement outcomes.

\begin{tabular}{|c|c|c|c|c|c|}
\hline Group & Pre-test & Post-test & $\mathbf{F}$ & \multicolumn{2}{|c|}{ Significance } \\
\hline \multirow{2}{*}{ t-score MOP } & \multirow{2}{*}{$-0.95 \pm 1.45$} & \multirow{2}{*}{$-0.84 \pm 1.42$} & 6.929 & $\mathrm{~T}:$ & $0.020 *$ \\
\hline & & & 0.566 & $\mathrm{t} \times \mathrm{g}:$ & 0.464 \\
\hline t-score PBO & $-0.99 \pm 0.79$ & $-0.93 \pm .074$ & 0.012 & G: & 0.915 \\
\hline \multirow{2}{*}{ \%FFMI MOP } & \multirow{2}{*}{$16.29 \pm 1.31$} & \multirow{2}{*}{$16.77 \pm 1.02$} & 6.206 & $\mathrm{~T}:$ & $0.026^{*}$ \\
\hline & & & 0.231 & $t \times g:$ & 0.638 \\
\hline \multirow[t]{2}{*}{ \%FFMI PBO } & $16.55 \pm 0.69$ & $16.88 \pm 1.19$ & 0.139 & G: & 0.715 \\
\hline & & & 7.154 & $\mathrm{~T}:$ & $0.018^{*}$ \\
\hline Lean Body Mass $(\mathrm{kg}) \mathrm{MOP}$ & $37.50 \pm 8.35$ & $38.22 \pm 7.91$ & 1.812 & $\mathrm{t} \times \mathrm{g}:$ & 0.200 \\
\hline Lean Body Mass $(\mathrm{kg})$ PBO & $37.88 \pm 3.74$ & $38.12 \pm 3.67$ & 0.002 & G: & 0.965 \\
\hline
\end{tabular}

Values are expressed as the mean \pm standard deviation. ${ }^{*} \mathrm{p}<0.05, \mathrm{~T}=$ time, $\mathrm{G}=$ group, DEXA: dual-energy X-ray absorptiometry, $\mathrm{t} \times \mathrm{g}=$ interaction of time and group.

Table 4. Changes in the calf circumference.

\begin{tabular}{|c|c|c|c|c|c|c|}
\hline & Group & Pre-test & Post-test & $\mathbf{F}$ & Sign & \\
\hline \multirow{3}{*}{ Calf circumference Left } & MOP & $33.94 \pm 3.51$ & $34.05 \pm 4.23$ & 0.488 & $\mathrm{~T}:$ & 0.496 \\
\hline & \multirow[b]{2}{*}{ PBO } & \multirow[b]{2}{*}{$34.13 \pm 2.70$} & \multirow[b]{2}{*}{$34.35 \pm 2.73$} & 0.054 & $\mathrm{t} \times \mathrm{g}:$ & 0.819 \\
\hline & & & & 0.022 & G: & 0.885 \\
\hline \multirow{3}{*}{ Calf circumference Right } & MOP & $34.31 \pm 3.89$ & $34.20 \pm 4.40$ & 0.001 & $\mathrm{~T}:$ & 0.978 \\
\hline & \multirow[b]{2}{*}{ PBO } & \multirow[b]{2}{*}{$34.31 \pm 3.02$} & \multirow[b]{2}{*}{$34.44 \pm 2.69$} & 0.286 & $\mathrm{t} \times \mathrm{g}:$ & 0.601 \\
\hline & & & & 0.005 & G: & 0.947 \\
\hline
\end{tabular}

Values are expressed as the mean \pm standard deviation. ${ }^{*} \mathrm{p}<0.05, \mathrm{~T}=$ time, $\mathrm{G}=$ group, $\mathrm{t} \times \mathrm{g}=$ interaction of time and group. 
Table 5. Changes in senior fitness test measurements.

\begin{tabular}{|c|c|c|c|c|c|c|}
\hline & Group & Pre-test & Post-test & $\mathbf{F}$ & \multicolumn{2}{|c|}{ Significance } \\
\hline \multirow{3}{*}{$\begin{array}{c}\text { Left } \\
\text { Grip Strength }\end{array}$} & $M \cap P$ & $1999+736$ & $2071+720$ & 0.120 & $\mathrm{~T}:$ & 0.734 \\
\hline & IVIUP & $19.99 \pm 1.36$ & $20.11 \pm / .29$ & 0.827 & $\mathrm{t} \times \mathrm{g}:$ & 0.379 \\
\hline & PBO & $20.80 \pm 3.59$ & $20.48 \pm 4.32$ & 0.01 & g: & 0.922 \\
\hline \multirow{3}{*}{$\begin{array}{c}\text { Right } \\
\text { Grip Strength }\end{array}$} & MOP & $20.79 \pm 6.81$ & $21.54 \pm 8.36$ & 0.714 & $\mathrm{~T}:$ & 0.412 \\
\hline & & & & 0.072 & $\mathrm{t} \times \mathrm{g}:$ & 0.792 \\
\hline & PBO & $22.49 \pm 1.82$ & $22.88 \pm 2.87$ & 0.306 & $\mathrm{~g}:$ & 0.589 \\
\hline \multirow{3}{*}{$\begin{array}{c}\text { Chair rise test } \\
\text { MOP }\end{array}$} & \multirow{3}{*}{$14.63 \pm 5.01$} & \multirow{3}{*}{\multicolumn{2}{|c|}{$15.75 \pm 3.92$}} & 1.583 & $\mathrm{~T}:$ & 0.229 \\
\hline & & & & 0.063 & $\mathrm{t} \times \mathrm{g}:$ & 0.805 \\
\hline & & & & 0.057 & G: & 0.815 \\
\hline $\begin{array}{c}2.4 \mathrm{~m} \text { up } \& \text { go } \\
\text { MOP }\end{array}$ & \multirow[t]{2}{*}{$6.98 \pm 2.19$} & \multirow[t]{2}{*}{$5.63 \pm 1.18$} & \multirow{3}{*}{$\begin{array}{r}16.537 \\
1.066\end{array}$} & $\mathrm{~T}:$ & \multicolumn{2}{|c|}{$0.001^{\star *}$} \\
\hline $4 \mathrm{mun} \& \mathrm{go}$ & & & & $\mathrm{t} \times \mathrm{g}:$ & & \\
\hline $\begin{array}{c}\text { 2.4m up\& go } \\
\text { PBO }\end{array}$ & $7.12 \pm 2.91$ & $6.32 \pm 2.50$ & & G: & & \\
\hline $\begin{array}{c}\text { One-leg stand } \\
\text { MOP }\end{array}$ & $10.78 \pm 10.23$ & $21.06 \pm 19.76$ & 8.836 & $\mathrm{~T}:$ & & \\
\hline $\begin{array}{c}\text { One-leg stand } \\
\text { PBO }\end{array}$ & $13.14 \pm 11.74$ & $14.78 \pm 11.74$ & 0.013 & $\mathrm{t} \times \mathrm{g}:$ & & \\
\hline
\end{tabular}

Values are expressed as the mean \pm standard deviation. $T=$ time, $G=$ group, $\mathrm{t} \times \mathrm{g}=$ =interaction of time and group.

\section{DISCUSSION}

Sarcopenia has recently been recognized as a geriatric syndrome characterized by musculoskeletal reduction, strength decrease, and a decline in physical function caused by aging ${ }^{28}$. It is considered a serious problem for older adults because it increases the risk of mobility disorders and falls and affects resulting mortality rates ${ }^{29}$. It is also a cause of major illnesses, such as diabetes, arthritis, cancer, and stroke ${ }^{30}$. Therefore, this study was conducted to test the effects of MOP intake on body composition and fitness of older adults (aged 65 years or older) with sarcopenia.

Marine polyphenols present in Phaeophyceae members have been reported to positively affect skeletal muscle by inhibiting the activity of alpha glucosidase, which decomposes consumed sugar into glucose, aids in muscle glucose uptake, and activates insulin signaling-related protein to affect glucose homeostasis. Furthermore, it inhibits the production of inflammatory cytokines in musculoskeletal cells ${ }^{31}$.

This study did not show a significant interaction effect; however, differences between the pre-test and post-test period in body composition factors, including SMM, bone density (t-score), \%FFMI, and intracellular fluid, were significant. Various plant polyphenols have been reported to have beneficial effects on muscle mass preservation by reversing mitochondrial dysfunction originating from oxidative stress-induced muscle wasting ${ }^{19}$. Further investigation of various polyphenols on muscle mass preservation is also suggested in a study ${ }^{32}$.

In a previous study, marine polyphenols extracted from Ecklonia cava, belonging to family Phaeophyceae, inhibited the formation of fat cells to impede the accumulation of fat tissues and decrease the production of triglycerides, thereby decreasing weight ${ }^{33}$. A previous study on obese patients reported that sea polyphenol (Ecklonia cava extract) intake resulted in a decrease in BMI, an increase in mRNA, and a decrease in lipid peroxidation-related genes, thereby having a positive effect on obesity-related metabolic disorders ${ }^{34}$. However, in this study, body composition did not show the beneficial effects of MOP, unlike previous research.

Furthermore, concerning changes in bone density after MOP intake, Ecklonia cava extract has been reported to alleviate bone loss, inhibit bone resorption, and increase the level of collagen to prevent post-menopausal bone $\operatorname{loss}^{35}$. In the present study, in addition to the results of the body composition variables, bone density did not show significant interaction effects.

Protein catabolism and muscle wasting occur because of aging and inflammation in the body, and cell volume decreases because of insufficient cell nutrition, with the volume of intracellular fluid decreasing as a result ${ }^{36}$. This study showed that MOP intake resulted in a significant increase in intracellular fluid over time. The anti-inflammatory function of the marine polyphenols ${ }^{37}$ inhibits muscle catabolism to affect the increase in intracellular fluid. Furthermore, the marine polyphenols consumed in the current study are phenolic compounds that contain highly hydrophilic phlorotannins because of the molecular bonding between water and hydrogen ${ }^{11}$. Thus, intracellular fluid was expected to increase, but the results only showed a significant effect by time, which was insufficient for an interaction effect.

Because sarcopenia is associated with decrease in skeletal muscles, decrease in strength, or decline in physical function, its symptoms can be assessed by simultaneously performing body composition and fitness tests ${ }^{28}$. Grip strength is an indicator that can objectively measure body 
strength $^{38}$. The thresholds for diagnosing sarcopenia in East Asians are $<26 \mathrm{~kg}$ for men and $<18 \mathrm{~kg}$ for women ${ }^{28}$. Gait speed, which combines agility and dynamic balance, is important for preventing falls ${ }^{39}$. Lower body strength and muscle power can be measured by performing the chair rise test, which is strongly related to daily life function and dysfunction ${ }^{40}$. The results of senior fitness test ${ }^{19}$ to determine the fitness and physical functions of the older adults in this study showed no significant differences between time or groups for grip strength or the chair rise test. There were significant differences by time in the $2.4 \mathrm{~m}$ up and go test, which measured dynamic balance. There were significant differences between the time duration and groups in the oneleg stand test, which assessed static balance. Thus, MOP intake affected static balance.

For older adults, a decrease in SMM can decrease bone thickness, create thinner cortices, and lower bending strength (lower section modulus), which directly affect balance and increase the risk of falls ${ }^{41}$. The SMM in this study showed a significant increase between pre-test and post-test periods in the MOP intake group, but there was no interaction effect. According to a previous study on mice, muscle hypertrophy with the polyphenol-rich fraction (E80) was promoted when reloading exercises were applied to the unloaded muscle. However, during the unloading period, E80 did not prevent muscle atrophy. This suggests that exercise combined with polyphenol intake could promote or increase muscle hypertrophy ${ }^{42}$.

A previous study reported that polyphenols activate physiological processes, including mitochondrial biogenesis in skeletal muscle ${ }^{43}$, thereby improving muscle-related fitness factors, such as agility and balance, and aerobic functions $s^{44}$. The consumption of oxygen in muscles increases during exercise. It generates ROS in the tissues, and senescent muscle appears to be more susceptible to oxidative stress during exercise because of age-related ultrastructural and biochemical changes that facilitate ROS formation ${ }^{45}$. The ability of polyphenols to remove ROS enables patients with sarcopenia to continue physical exercise ${ }^{46}$. The MOP consumed in this study was also a strong antioxidant. Thus, elimination of the activated oxygen, which is overproduced because of exercise $^{11}$, enables continued exercise. Although some variables, such as SMM, increased with the MOPs, we could not track all the nutritional intake of the participants, and this could be a limitation of this study.

The measurements and analyses to examine the changes in the body composition based on MOP intake did not show significant effects with respect to SMM, bone density (t-score), and the \%FFMI. These results indicated that MOP intake might require further research to identify its effects on body composition.

In the senior fitness test conducted to examine changes in fitness, there was a significant difference between time duration for the $2.4 \mathrm{~m}$ up and go test. There were significant differences between time duration and groups in the one-leg stand test, which indicates static balance. Thus, MOP intake may be effective in improving the static balance. Although the analyses did not show interaction effects for muscle mass increase, marine algal polyphenols belonging to phlorotannin regulate myogenesis by downregulating Smad signaling, a negative regulator, and upregulating insulin-like insulin growth factor-1 signaling, a positive regulator ${ }^{15}$. This might have affected the one-leg stand test, which is related to muscle function.

Additional studies on the effect of MOP intake and exercise intervention on body composition and fitness of older adults are necessary in the future.

\section{ACKNOWLEDGEMENTS}

This study is funded by BotaMedi, Inc.

\section{REFERENCES}

1. Statistics Korea. Major demographic indicators [internet]. Daejeon: statistics Korea [cited 2019 April 12]. http://kostat.go.kr.

2. Hong SM, Choi WH. Clinical and physiopathological mechanism of sarcopenia. Korean J Med. 2012;83:444-54.

3. Cruz-Jentoft AJ. Sarcopenia: european consensus on definition and diagnosis: report of the european working group on sarcopenia in older people. Age Ageing. 2010;39:412-23.

4. Roubenoff R. Sarcopenia: a major modifiable cause of frailty in the elderly. J Nutr Health Aging. 2000;4:140-2.

5. Janssen I, Shepard DS, Katzmarzyk PT, Roubenoff R. The healthcare costs of sarcopenia in the United States. J Am Geriatr Soc. 2004;52:80-5.

6. Meng SJ, Yu LJ. Oxidative stress, molecular inflammation and sarcopenia. Int J Mol Sci. 2010;11:1509-26.

7. Rong, YD, Bian AL, Hu HY, Ma Y, Zhou XZ. Study on relationship between elderly sarcopenia and inflammatory cytokine IL-6, anti-inflammatory cytokine IL-10. BMC Geriatr. 2018;18:308.

8. Maggio M, Lauretani F, Ceda GP. Sex hormones and sarcopenia in older persons. Curr Opin Clin Nutr Metab Care. 2013;16:3-13.

9. Beckman KB, Ames BN. The free radical theory of aging matures. Physiol Rev. 1998;78:547-81.

10. Moylan JS, Reid MB. Oxidative stress, chronic disease, and muscle wasting. Muscle Nerve. 2007;35:411-29.

11. Beasley JM, Shikany JM, Thomson CA. The role of dietary protein intake in the prevention of sarcopenia of aging. Nutr Clin Pract. 2013;28:684-90.

12. Morley JE, Argiles JM, Evans WJ, Bhasin S, Cella D, Deutz NEP Doehner W, Fearon KCH, Ferrucci L, Hellerstein MK, Kalantar-Zadeh K, Lochs H, MacDonald N, Mulligan K, Muscaritoli M, Ponikowski P, Posthauer ME, Fanelli FP, Schambelan M, Schols AMWJ, Schuster MW, Anker SD. Nutritional recommendations for the management of sarcopenia. J Am Med Dir Assoc. 2010;11:3916.

13. Barbosa M, Lopes G, Ferreres F, Andrade PB, Pereira DM, Gil-Izquierdo Á, Valentão P. Phlorotannin extracts from fucales: marine polyphenols as bioregulators engaged in inflammation-related mediators and enzymees. Algal research. 2017;28:1-8.

14. Lomartire S, Marques JC, Gonçalves AM. An overview to the health benefits of seaweeds consumption. Marine Drugs. 2021; 19:341. 
15. Kim SY, Lee JH, Kang N, Kim KN, Jeon YJ. The effects of marine algal polyphenols, phlorotannins, on skeletal muscle growth in C2C12 muscle cells via Smad and IGF-1 signaling pathways. Marine drugs. 2021;19:266.

16. Fernando IS, Kim M, Son KT, Jeong Y, Jeon YJ. Antioxidant activity of marine algal polyphenolic compounds: a mechanistic approach. J Med Food. 2016;19:615-28.

17. Singh IP, Bharate SB. Phloroglucinol compounds of natural origin. Nat Prod Rep. 2006;23:558-91.

18. Wijesekara I, Yoon NY, Kim SK. Phlorotannins from ecklonia cava (phaeophyceae): biological activities and potential health benefits. Biofactors. 2010;36:408-14.

19. Nikawa T, Ulla A, Sakakibara I. Polyphenols and their effects on muscle atrophy and muscle health. Molecules. 2021;26:4887.

20. Studenski SA, Peters KW, Alley DE, Cawthon PM, McLean RR, Harris TB, Ferrucci L, Guralnik JM, Fragala MS, Kenny AM, Kiel DP, Kritchevsky SB, Shardell MD, Dam T-T L, Vassileva MT. The FNIH sarcopenia project: rationale, study description, conference recommendations, and final estimates. J Gerontol A Biol Sci Med Sci. 2014;69:547-58.

21. American College of Sports Medicine, editors. ACSM's Health-related physical fitness assessment manual 2013. Baltimore, MD. Lippincott Williams \& Wilkins, 2014.

22. Rubbieri G, Mossello E, Di Bari M. Techniques for the diagnosis of sarcopenia. Clin Cases Miner Bone Metab. 2014;11:181-4.

23. Jeong J, Yoon J, Oh, J. The correlation between hand grip strength and knee strength, proprioception and balance in elderly. Sport Sci. 2016;34:55-62.

24. Whitney SL, Wrisley DM, Marchetti GF, Gee MA, Redfern MS, Furman JM: Clinical measurement of sit-to-stand performance in people with balance disorders: validity of data for the five-timessit-to-stand test. Phys Ther. 2005;85:1034-45.

25. Rikli RE, Jones CJ. Senior Fitness Test Manual. Champaign, IL. Human Kinetics. 2013.

26. Rossiter-Fornoff JE, Wolf SL, Wolfson LI, Buchner DM. FICSIT Group. A cross-sectional validation study of the FICSIT common data base static balance measures. Frailty and Injuries: cooperative Studies of Intervention Techniques. J Gerontol A Biol Sci Med Sci. 1995;50:M291-7.

27. Oh JK, Shin YO, Yoon JH, Kim SH, Shin HC, Hwang HJ. Effect of supplementation with Ecklonia cava polyphenol on endurance performance of college students. Int J Sport Nutr Exerc Metab. 2010;20;72-9.

28. Chen LK, Liu LK, Woo J, Assantachai P, Auyeung TW, Bahyah KS, Chou MY, Chen LY, Hsu PS, Krairit O, Lee JSW, Lee WJ, Lee Y, Liang CK, Limpawattana P, Lin CS, Peng LN, Satake S, Suzuki T, Won CW, Wu CH, Wu SN, Zhang T, Zeng P, Akishita M, Arai H. Sarcopenia in asia: consensus report of the asian working group for sarcopenia. J Am Med Dir Assoc. 2014;15 95-101.

29. Jang HC. How to diagnose sarcopenia in Korean older adults? Ann Geriatr Med Res. 2018;22:73-9.

30. Janssen I, Heymsfield SB, Ross R. Low relative skeletal muscle mass (sarcopenia) in older persons is associated with functional impairment and physical disability. J Am Geriatr Soc. 2002;50:88996.

31. Kang SY, Kim E, Kang I, Lee M, Lee Y. Anti-diabetic effects and anti-inflammatory effects of laminaria japonica and hizikia fusiforme in skeletal muscle: in vitro and in vivo model. Nutrients.
2018:10:491.

32. Salucci S, Falcieri E. Polyphenols and their potential role in preventing skeletal muscle atrophy. Nutr Res. 2020;74:10-22.

33. Kim SY, Yun IJ, Kwon CJ, Choi J, Kim Y-M, Kang M-H, Lee M-K, Nam T. The effects of anti-obesity on enzyme-treated ecklonia cava extracts. Korean J Fish Aquat Sci. 2014;47:363-9.

34. Lee HJ, Kwon O, Kim JY. Supplementation of a polyphenol extract from Ecklonia cava reduces body fat, oxidative and inflammatory stress in overweight healthy subjects with abdominal obesity: a randomized, placebo-controlled, double-blind trial. J Funct Foods. 2018;46:356-64.

35. Kang SL, Kim MH. The effect of ecklonia cava extracts on bone turnover markers in ovariectomized rats. Korean J Life Sci. 2009; 19:1841-6.

36. Johansen KL, Dalrymple LS, Delgado C, Kaysen GA, Kornak J, Grimes B, Chertow GM. Association between body composition and frailty among prevalent hemodialysis patients: a US renal data system special study. J Am Soc Nephrol. 2014;25:381-9.

37. Lee JC, Hou MF, Huang HW, Chang FR, Yeh C-C, Tang J-Y, Chang H-W. Marine algal natural products with anti-oxidative, anti-inflammatory, and anticancer properties. Cancer Cell Int. 2013; 13:55

38. Harimoto N, Yoshizumi T, Izumi T, Motomura T, Harada N, Itoh S, Ikegami T, Uchiyama H, Soejima Y, Nishie A, Kamishima T, Kusaba R, Shirabe K, Maehara Y. Clinical outcomes of living liver transplantation according to the presence of sarcopenia as defined by skeletal muscle mass, hand grip, and gait speed. Transplant Proc. 2017:49:2144-52

39. Shubert TE. Evidence-based exercise prescription for balance and falls prevention: a current review of the literature. J Geriatr Phys Ther. 2011;34:100-8.

40. Puthoff ML, Nielsen DH. Relationships among impairments in lower-extremity strength and power, functional limitations, and disability in older adults. Phys Ther. 2007;87:1334-47.

41. Szulc P, Beck TJ, Marchand F, Delmas PD. Low skeletal muscle mass is associated with poor structural parameters of bone and impaired balance in elderly men-The MINOS study. J Bone Miner Res. 2005;20:721-9.

42. Aoki Y, Ozawa T, Numata, O, Takemasa T. High-molecular-weight polyphenol-rich fraction of black tea does not prevent atrophy by unloading, but promotes soleus muscle mass recovery from atrophy in mice. Nutrients. 2019;11:2131.

43. Davis JM, Murphy EA, Carmichael MD, Davis B. Quercetin increases brain and muscle mitochondrial biogenesis and exercise tolerance. Am J Physiol. 2009;296:R1071-7.

44. Yoon JH, Oh JK. Effect of seaweed extracts administration on aerobic capacity, exercise fatigue and concentration in elite athletes. Korea J Sport. 2013;11:287-97.

45. Fulle S, Protasi F, Di Tano G, Pietrangelo T, Beltramin A, Boncompagni $S$, Vecchie L, Fanò $G$. The contribution of reactive oxygen species to sarcopenia and muscle ageing. Exp Gerontol. 2004;39:17-24.

46. Kang SB, Cha HJ, Ha HD. The effects of aerobic exercise capacity on free oxygen radical in blood during submaximal exercise in rowing ergometer. J Navig Port Res. 2010;34:757-62. 